\title{
Geometric Parameters and Behavior Factor of Knee-Braced Steel Frames Using Nonlinear Static Pushover (NSP) Analyses
}

\author{
Majid Anoushehei ${ }^{1} \&$ Farhad Daneshjoo ${ }^{1}$ \\ ${ }^{1}$ Department of Civil and Environmental Engineering, Tarbiat Modares University, Tehran, Iran \\ Correspondence: Farhad Daneshjoo, Department of Civil and Environmental Engineering, Tarbiat Modares \\ University, Jalal Ale Ahmad Highway, P. O. Box: 14115-111, Tehran, Iran. Tel: 9821-8288-3384. E-mail: \\ danesh_fa@modares.ac.ir
}

Received: May 27, 2016

Accepted: June 29, 2016

Online Published: July 29, 2016

doi:10.5539/mas.v10n11p110

URL: http://dx.doi.org/10.5539/mas.v10n11p110

\begin{abstract}
During the recent years, the new knee-braced frame (KBF) system has been interested to achieve a proper seismic behavior. Briefly introducing KBF, the present study evaluates the geometric parameters and behavior factor of multi-story knee-braced steel frames. The studied models include three-, five- and eight-story steel $\mathrm{CBFs}$, EBFs and KBFs. Using linear static analyses, the present study evaluates lateral stiffness of knee-braced frames and plots their co-stiffness curves. Using co-stiffness curves, then, the best range is determined for geometric parameters of KBFs to achieve the proper stiffness. In addition, ductility-related seismic force reduction factor $(\mathrm{R} \mu)$, over strength factor $(\mathrm{RS})$, and behavior factor $(\mathrm{R})$ are calculated for the frames using Nonlinear Static Pushover (NSP) analyses, and compared with the corresponding concentric and eccentric frames.
\end{abstract}

Keywords: Knee-braced frame (KBF), stiffness, ductility, over strength factor, behavior factor

\section{Introduction}

The modern designs of earthquake resistant buildings have to consider a series of factors including resistance, stiffness, and ductility. Lack of a factor makes the structure unsafe against earthquake. Conducted studies show that moment-resisting frames (MRFs) are highly ductile and excellent energy dissipation capacities; however, they are relatively flexible and uneconomic when high stiffness is required. In contrast, concentric-braced frames (CBF) show considerable resistance and stiffness in linear ranges; but, they show low and weak energy intake and ductility due to buckling braces in nonlinear ranges. Eccentric-braced frames (EBFs) combine inelastic behavior and energy intake of flexural frames with resistance and stiffness of CBFs and show a more suitable behavior. But, nonlinear behaviors of these frames are mostly related to beams (Nateghi Elahi \& Akbarzadegan, 1996).

During the recent years, a new bracing system called knee-braced frame (KBF) has been developed to achieve a better seismic behavior and eliminate the defects of the other bracing systems. This system involves a diagonally-braced frame, in which at least one end of diagonal brace is connected to the knee member, which is diagonally placed between beams and columns. Diagonal bracing provides system stiffness, while ductility is influenced by severe lateral loads through yielding of knee member. A properly developed knee member acts as a ductile fuse preventing buckling of diagonal brace (Balendra, Sam, \& Liaw, 1990). More discussions are provided in (Anoushehei \& Daneshjoo, 2005) and (Daneshjoo \& Asgari, 2003).

The present paper studies multi-story knee-braced frames to determine their best range of geometric parameters in order to achieve a proper stiffness. Thus, lateral stiffness of multi-story KBFs is considered as a function of geometric parameters and member characteristics, and the effects of these factors are separately examined on their lateral stiffness. The present study also determines ductility-related seismic force reduction factor $(\mathrm{R} \mu)$, over strength factor (RS), and behavior factor (R) for these frames. The software RAMPERFORM was used for nonlinear static analysis of studied models to extract their base shear-displacement of roof curves separately. Using the principles of behavior factor, explained as follows, the value of behavior factor are calculated for the studied frames. 


\section{Studied Models and Their Loads}

To develop the studied models, a residential building has been considered. The earthquake resistant system for this building is developed for three-, five-, and eight-story forms using MRF system and TKBFs, EBFs, and CBFs. Thus, EBFs are initially developed according to UBC Code (UBC, 1997). To develop TKBFs and CBFs, sections of beams, columns and braces are considered similar to EBFs. Therefore, moment resisting frame and bracing member become identical in the above three systems, and the only difference is for arrangement of braces. As a result, the consumed steel is almost equal for the studied models and their main periods are adjacent. Thus, the behaviors of these models can be compared. Iranian National Building Code-Part6 (INBC-6, 2013) and Iranian Standard No 2800 (Standard-2800, 2014) were used to develop models for gravity loads and seismic loads, respectively, and the following forces were obtained:

Large gravity load including live and dead loads on beams: $2.995 \mathrm{t} / \mathrm{m}$ for stories, and $2.1 \mathrm{t} / \mathrm{m}$ for roof.

Centric gravity load including live and dead loads on columns: 5.99 ton for stories, and 4.2 ton for roof.

Base shear value resulted from seismic lateral load: 13.7 ton for three-story, 23.23 ton for five-story, and 35.58 ton for eight-story models, distributed in height according to the Code.

To develop EBFs according to UBC Code (UBC, 1997), the length of beam should not be greater than 1.6MP/VP when the link beam is connected to the column in one end. In that case, shear yield will dominate link beam. On the other hand, energy intake and dissipation of shear yield will be relatively more than flexural yield of link beam (Nateghi Elahi \& Akbarzadegan, 1996). This is why the link beam is designed according to the shear yield. Table.1 shows the characteristics of EBF models, three-story TKBFs, EBFs and CBFs, as an example.
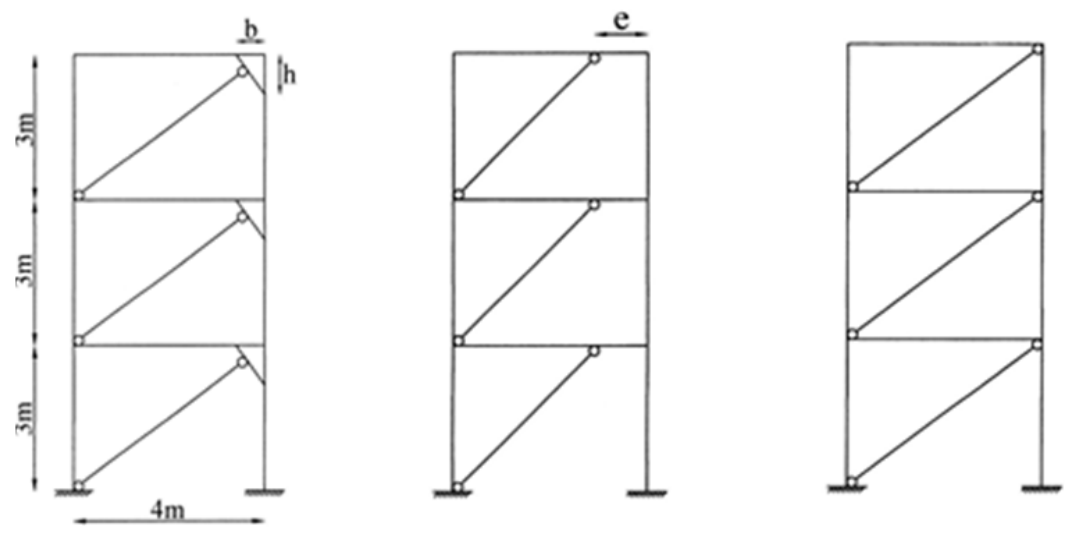

Figure 1. The studied three-story TKBFs, EBFs and CBFs

Table 1. Characteristics of EBFs with a $45 \mathrm{~cm}$ link beam

\begin{tabular}{llllll}
\hline Models & Story & Link beam & Beam & Column & Brace \\
\hline EBF-3ST & $1,2,3$ & IPE 220 & IPE 220+2PL90×15 & IPB 200 & 2UNP 140 \\
& $1,2,3$ & IPE 270 & IPE 270+2PL100×8 & IPB 260 & 2UNP 160 \\
EBF- 5ST & 4,5 & IPE 220 & IPE 220+2PL90×15 & IPB 160 & 2UNP 140 \\
& $1,2,3$ & IPE 360 & IPE360 & IPB 450 & 2UNP 220 \\
EBF- 8ST & $4,5,6$ & IPE 300 & IPE 300+ 2PL50×10 & IPB 260 & 2UNP 180 \\
& 7,8 & IPE 220 & IPE 220+ 2PL90×15 & IPB 160 & 2UNP 140 \\
\hline
\end{tabular}

\section{Lateral Stiffness of KBF}

Figure 2 shows a multi-story KBF, in which knee member is placed at the higher end of diagonal brace (T-KBF). As another design, the knee member can be located below (B-KBF) or at the both ends of the diagonal brace (D-KBF) (Balendra, Sam, Liaw, \& Lee, 1991). According to the results of (Daneshjoo \& Asgari, 2003), the present paper studies the behaviors of T-KBFs. 


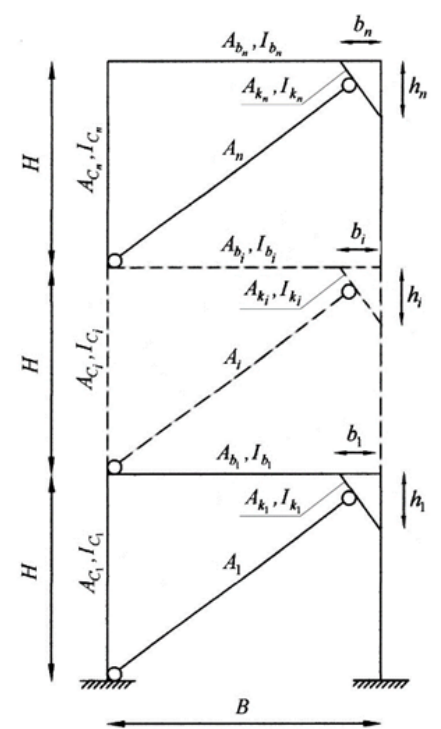

Figure 2. Effective parameters of lateral stiffness of KBFs

According to the results of (Daneshjoo \& Asgari, 2003) for single-story frames, Eq. (1) shows the stiffness equation of an n-story frame in a dimensionless form:

$$
\frac{K_{t}}{E I_{C} / H^{3}}=\varphi \quad\left[\left(\frac{H}{B}, \frac{h}{H}, \frac{b}{B}, \frac{A}{A_{K}}, \frac{I_{K}}{I_{C}}\right)_{j}\right] \quad, \quad j=1,2, \ldots, n
$$

where,

$H$ and $B \quad$ : Story height and frame width

$h$ and $b \quad$ : Parameters indicating knee member

$A, A_{K}, A_{c} \quad$ : Sections of column, knee, and brace

$I_{K}, I_{C} \quad$ : Moment of inertia for column and knee

E : Elasticity module

$j \quad$ : Number of stories

$K_{t} \quad$ : Lateral stiffness of frame

Now, the effect of the above parameters can be separately studied on the lateral stiffness of KBFs. To calculate the lateral stiffness of structure, a certain lateral force can be applied on the roof level. The structure displacement can be obtained in the roof level using linear static analysis. The lateral stiffness of structure is obtained by dividing force to displacement. It is noteworthy that the present study considers the above ratios constant in different stories to evaluate the lateral stiffness of KBFs. 

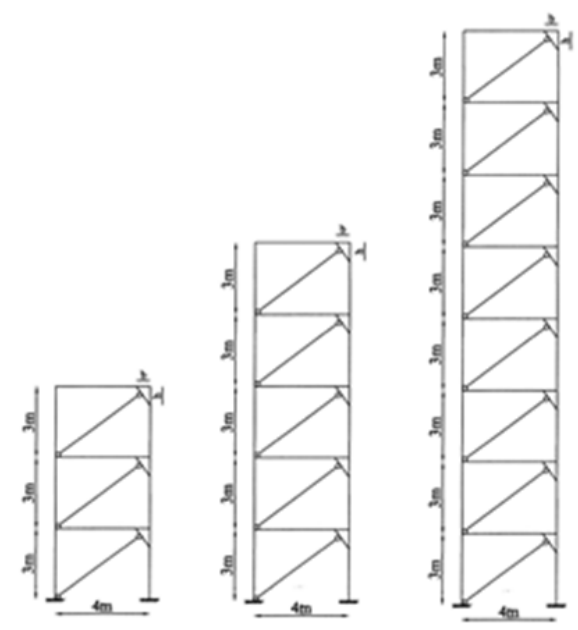

Figure 3. The studied multi-story TKBFs

\subsection{Effect of $\frac{\boldsymbol{b}}{\boldsymbol{B}}$ and $\frac{\boldsymbol{h}}{\boldsymbol{H}}$ on lateral Stiffness of Multi-Story TKBFs}

To evaluate the effect of knee member location on lateral stiffness of multi-story TKBFs by keeping the other different ratios constant, certain constant sections are considered for this member according to Table 2. 121 different geometric models are obtained by changing parameters $\frac{b}{B}$ and $\frac{h}{H}$ ranging from zero to one $(0.0,0.1$, $0.2, \ldots, 1)$ for three-, five- and eight-story TKBF models, separately. Using linear static analyses, then, lateral stiffness is separately determined for the geometric models.

Table 2. Characteristics of knee members for TKBFs

\begin{tabular}{lll}
\hline Frame & Story & Knee \\
\hline TKBF- 3ST & $1,2,3$ & BOX 100×6.3 \\
TKBF- 5ST & $1,2,3$ & BOX 120×6 \\
& 4,5 & BOX 100×6.3 \\
& $1,2,3$ & BOX 140×6 \\
TKBF- 8ST & $4,5,6$ & BOX 120×6 \\
& 7,8 & BOX 100×6.3 \\
\hline
\end{tabular}

The dimensionless ratio $\frac{\mathrm{K}}{\mathrm{EI}_{\mathrm{C}} / \mathrm{H}^{3}}$ is determined by dividing the lateral stiffness of structure by stiffness of the first-story column. Therefore, values $\left(\frac{b}{B}, \frac{h}{H}, \frac{K}{E I_{C} / H^{3}}\right)$ specify a point in the 3D space for each studied frame. These points are interpolated by the software MATLAB to find the best possible procedure. To observe more accurately, co-stiffness curves of frames are separately determined by MATLAB and plotted similar to topographic plans. By evaluating $\frac{b}{B}$ and $\frac{h}{H}$ simultaneously, the angle between knee member and beam, column and brace are automatically inserted in the analyses, and several other forms are also examined. The results are shown in Figs. 4 to 10. According to the figures, it can be concluded that:

The point $\frac{b}{B}=\frac{h}{H}=0$ is related to $\mathrm{CBF}$, in which the maximum value is obtained for lateral stiffness. 
The points $\frac{h}{H}=0, \frac{b}{B}=1, \frac{h}{H}=1$ and $\frac{b}{B}=0$ are related to MRF, in which the minimum value is obtained for lateral stiffness.

The range $0<\frac{\mathrm{b}}{\mathrm{B}}<1$ and $\frac{\mathrm{h}}{\mathrm{H}}=0$ is related to EBF, in which no considerable stiffness is obtained in $0.5<\frac{b}{B}<$ 1 range. Increment of stiffness clearly starts from $\frac{b}{B} \leq 0.5$. As $\frac{b}{B}$ decreases, stiffness is considerably increased.

To achieve a proper stiffness, the best range for $\frac{b}{B}$ and $\frac{h}{H}$ in TKBFs matches with area $S_{3}$ in Fig. 10. This range, which can be written as $\left(\frac{b}{B}+\frac{h}{H}\right)<0.6,0.1<\left(\frac{b}{B}, \frac{h}{H}\right)<0.4$ is common in three-, five- and eight-story frames.

\subsection{Effect of $\frac{A}{A_{K}}$ and $\frac{I_{K}}{I_{C}}$ on Lateral Stiffness of Multi-Story TKBFs}

To evaluate the effect of sectional characteristics of members on lateral stiffness of KBFs, different analytic models are separately obtained for three-, five- and eight-story TKBFs by changing parameters $\frac{A}{A_{K}}$ and $\frac{I_{K}}{I_{C}}$ separately, and keeping the other considered ratios constant in Eq. (1). Then, the lateral stiffness of models is separately calculated using linear static analyses by the previously explained method. The results are plotted as $\frac{K}{E I_{C} / H^{3}}$ in terms of $\frac{A}{A_{K}}$ and $\frac{I_{K}}{I_{C}}$, in which $E I_{C} / H^{3}$ is related to the first-story column.

Figures 11 to 13 show the effects of changes in cross-section of braces on stiffness of multi-story TKBFs. As the figures show, the lateral stiffness of TKBFs increases rapidly as cross-section of braces rise; however, it is limited to a certain range, above which the stiffness slowly increases.

Figures 14 to 16 show the effect of moment of inertia for knee member on stiffness of multi-story TKBFs. Accordingly, lateral stiffness of TKBFs fast increases as moment of inertia for knee member rises; however, it is limited to a certain range, above which stiffness slowly increases.

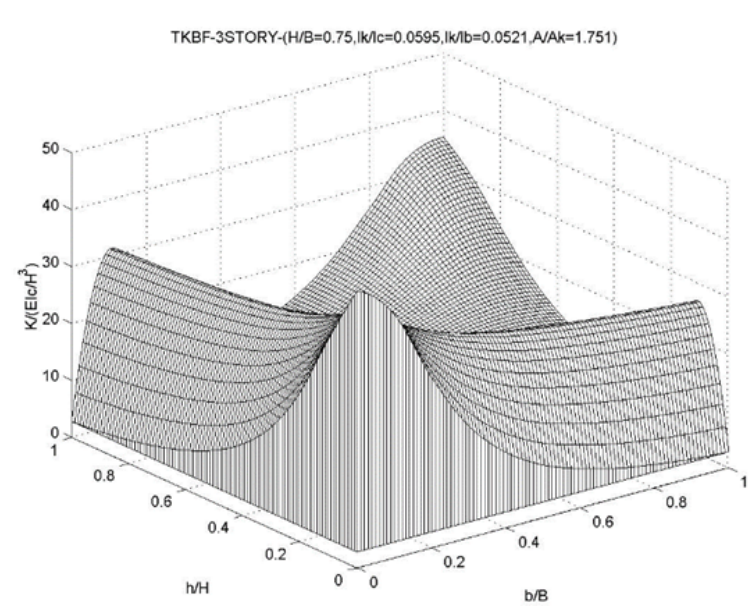

Figure 4. 3D curve of stiffness for 3-story TKBF

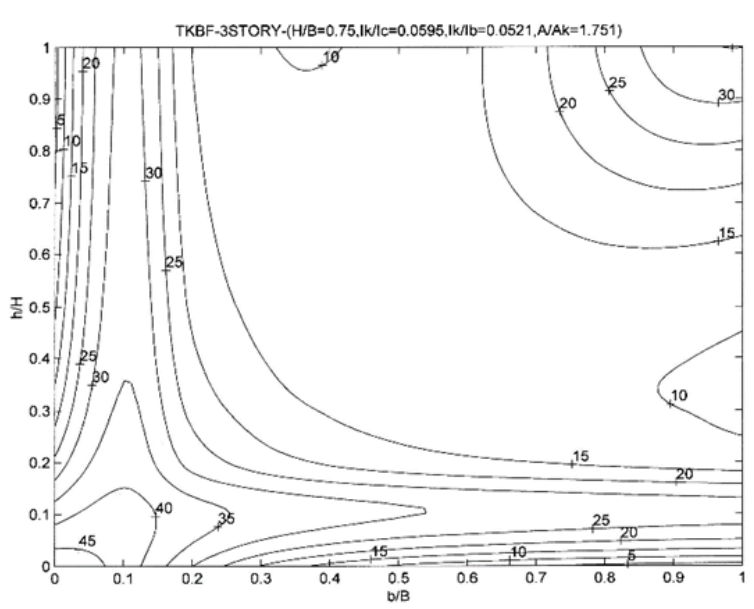

Figure 5. Co-stiffness curves for 3-story TKBFs 


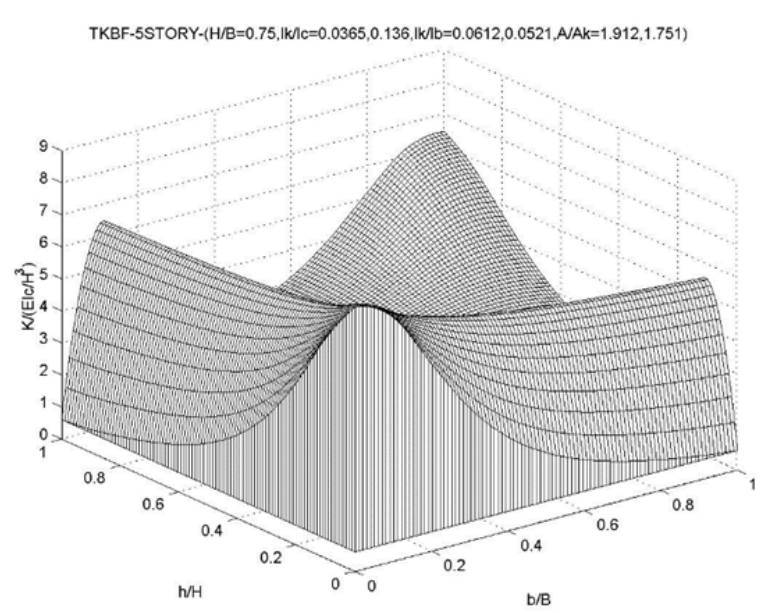

Figure 6. 3D curve of stiffness for 5-story TKBF

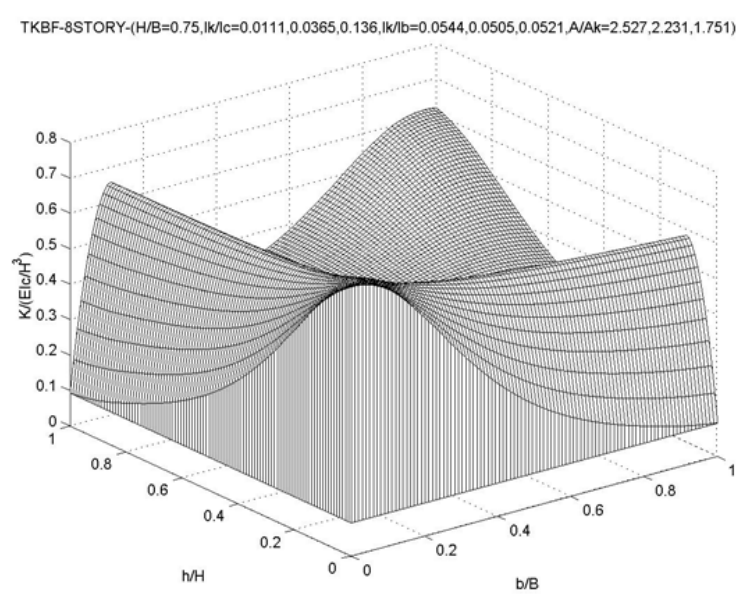

Figure 8. 3D curve of stiffness for 8 -story TKBF

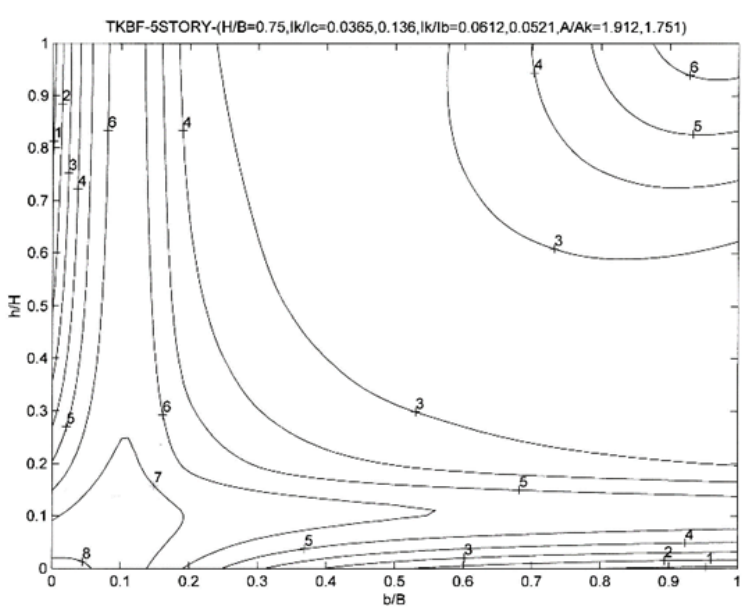

Figure 7. Co-stiffness curves for 5 -story TKBFs

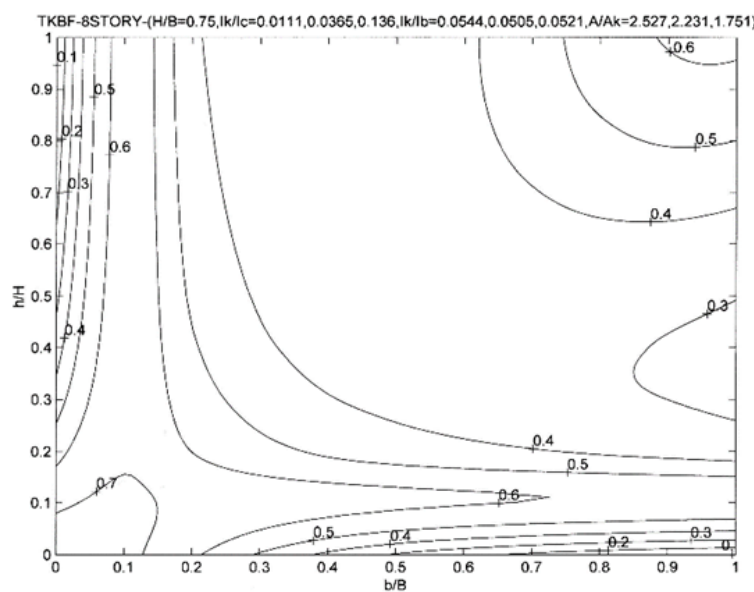

Figure 9. Co-stiffness curves for 8 -story TKBFs

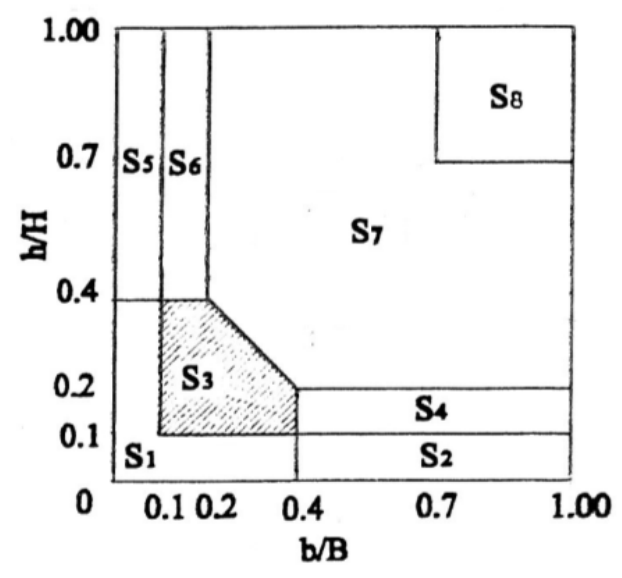

Figure 10. Suitable area of $\frac{b}{B}$ and $\frac{h}{H}$ for stiffness of multi-story TKBFs 


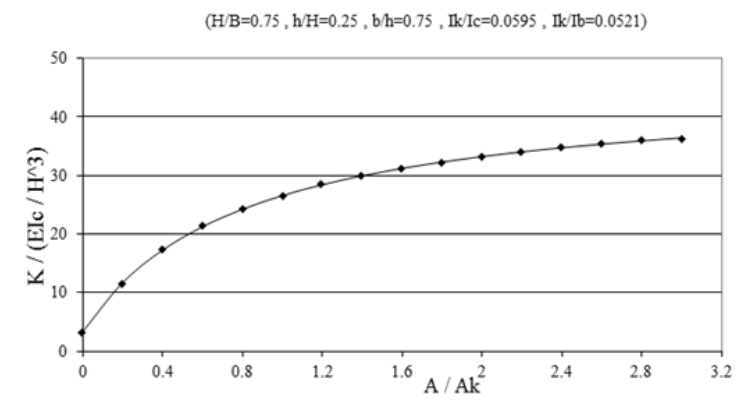

Figure 11. Effect of A/AK on lateral stiffness of 3-story TKBF

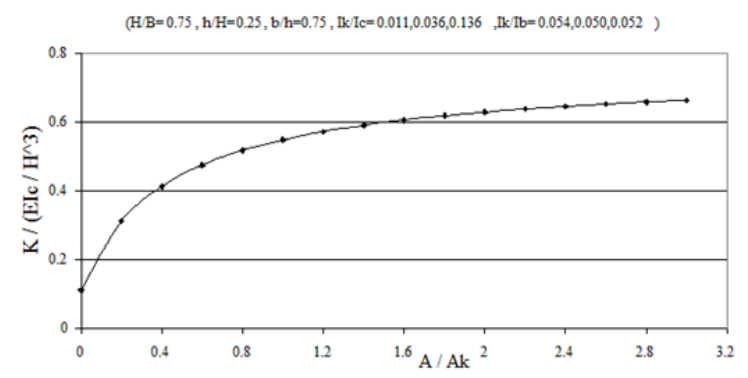

Figure 13. Effect of A/AK on lateral stiffness of 8-story TKBF

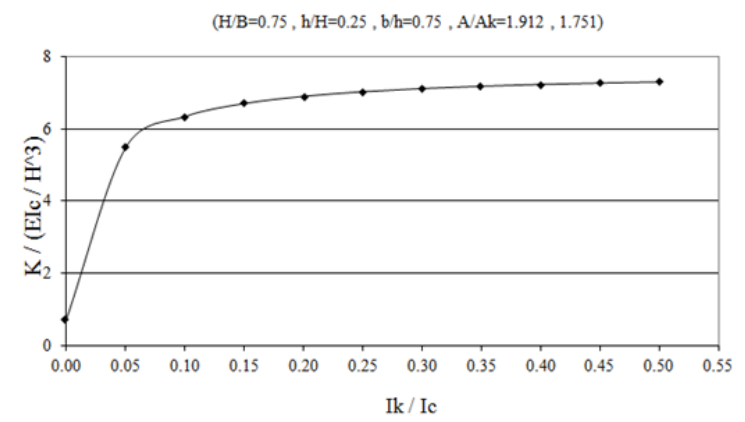

Figure 15 . Effect of $\mathrm{I}_{\mathrm{K}} / \mathrm{I}_{\mathrm{C}}$ on lateral stiffness of 5-story TKBF

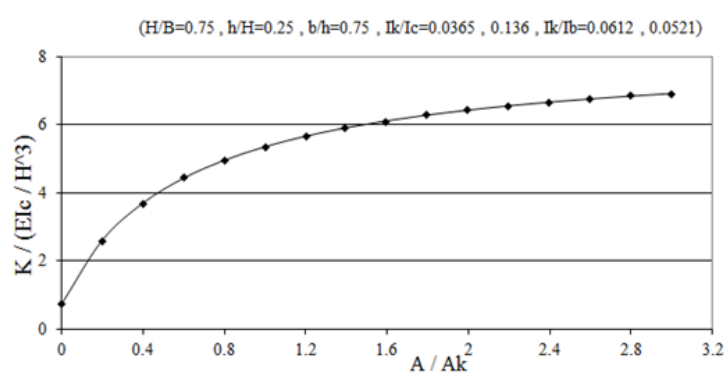

Figure 12. Effect of A/AK on lateral stiffness of 5-story TKBF

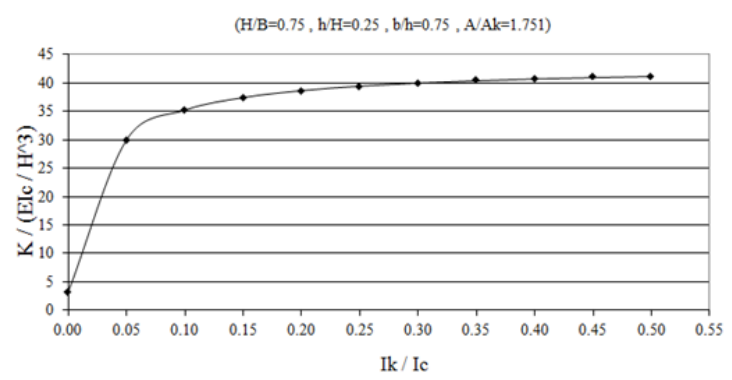

Figure 14. Effect of IK/IC on lateral stiffness of 3-story TKBF

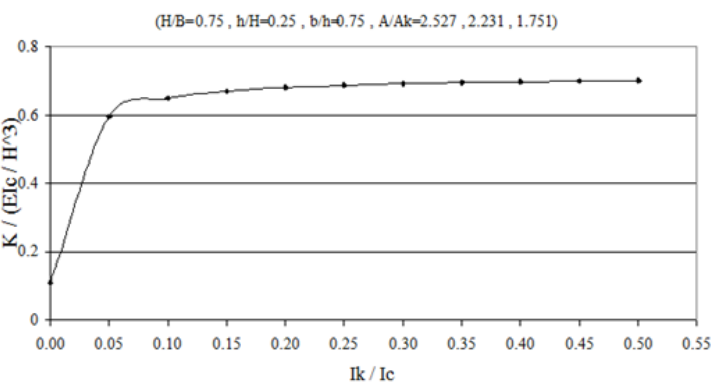

Figure 16. Effect of $\mathrm{I}_{\mathrm{K}} / \mathrm{I}_{\mathrm{C}}$ on lateral stiffness of 8-story TKBF

\section{Nonlinear Static Analyses}

Nonlinear Static Pushover (NSP) analyses are used to evaluate the behaviors of studied models in inelastic range. In this method, the earthquake-related lateral load is statically applied on the structure in an increasingly gradual way. This continues until the displacement reaches to a certain value in a certain point under the lateral load, or the structure collapses. According to the suitable area of $\frac{b}{B}$ and $\frac{h}{H}$ determined in section 3.1 , five different geometries are separately considered for knee members of three-, five- and eight-story TKBF models. Knee members are designed considering available forces. Tables 3 and 4 show geometric characteristics of TKBFs and characteristics of their knee members, respectively. 
Table 3. Geometric characteristics of studied TKBFs

\begin{tabular}{lllllll}
\hline Model & $\mathrm{B}(\mathrm{m})$ & $\mathrm{H}(\mathrm{m})$ & $\mathrm{h} / \mathrm{H}$ & $\mathrm{b} / \mathrm{h}$ & $\mathrm{h}(\mathrm{m})$ & $\mathrm{b}(\mathrm{m})$ \\
\hline TKBF-1 & 4.00 & 3.00 & 0.15 & 0.75 & 0.45 & 0.3375 \\
TKBF-2 & 4.00 & 3.00 & 0.20 & 0.75 & 0.60 & 0.4500 \\
TKBF-3 & 4.00 & 3.00 & 0.25 & 0.75 & 0.75 & 0.5625 \\
TKBF-4 & 4.00 & 3.00 & 0.30 & 0.75 & 0.90 & 0.6750 \\
TKBF-5 & 4.00 & 3.00 & 0.35 & 0.75 & 1.05 & 0.7875 \\
\hline
\end{tabular}

Table 4. Characteristics of knee members for the studied TKBFs

\begin{tabular}{|c|c|c|c|c|c|c|}
\hline Model & Story & TKBF-1 & TKBF-2 & TKBF-3 & TKBF-4 & TKBF-5 \\
\hline TKBF-3ST & $1,2,3$ & Box $120 \times 5.6$ & Box $120 \times 6.3$ & Box140×5.6 & Box $140 \times 6.3$ & Box $140 \times 7.1$ \\
\hline \multirow{3}{*}{ TKBF- 5ST } & $1,2,3$ & & & & & $50 \times 8$ \\
\hline & 4,5 & & & & & $0 \times 7.1$ \\
\hline & $1,2,3$ & Bo: & & & & $0 \times 8$ \\
\hline \multirow[t]{2}{*}{ TKBF- 8ST } & $4,5,6$ & & & & & $80 \times 8$ \\
\hline & 7,8 & Box $120 \times 5.6$ & Box $120 \times 6.3$ & Box $140 \times 5.6$ & Box $140 \times 6.3$ & Box $140 \times 7.1$ \\
\hline
\end{tabular}

Therefore, considering EBFs and CBFs, there are totally 21 different analytic models for which the following assumptions are used to conduct nonlinear static analyses:

Lateral load was distributed according to Iranian Standard No 2800 (Standard-2800, 2014);

Documents of FEMA 273 was used for properties of nonlinear joints (FEMA-273, 1997);

Stiffness strain was ignored;

Lateral load was imposed in a direction to which braces compressively acted. Therefore, braces would possibly buckle;

Analysis continues until one of the following occurs:

At least one brace buckles;

The relative displacement between two stories exceed the permissible value 0.02H According to FEMA 273 (FEMA-273, 1997);

A mechanism develops in the structure.

The software RAMPERFORM was used to conduct the nonlinear static analyses and the results were separately extracted as base shear-displacement of roof curves for frames. For example, some curves can be observed in Figs. 17 to 22. Generally, the conducted analyses show that the ductility control modes for TKBFs and EBFs exceed the relative displacement between two stories in the permissible code, while ductility control modes for CBFs are brace buckling.

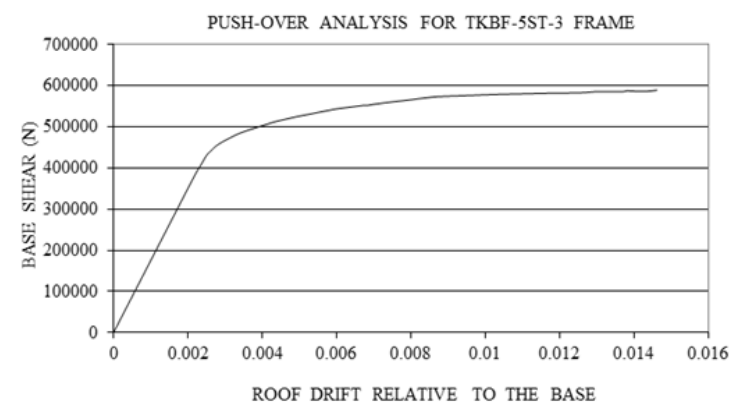

Figure 17. Push over curve for 5 -story TKBF-3

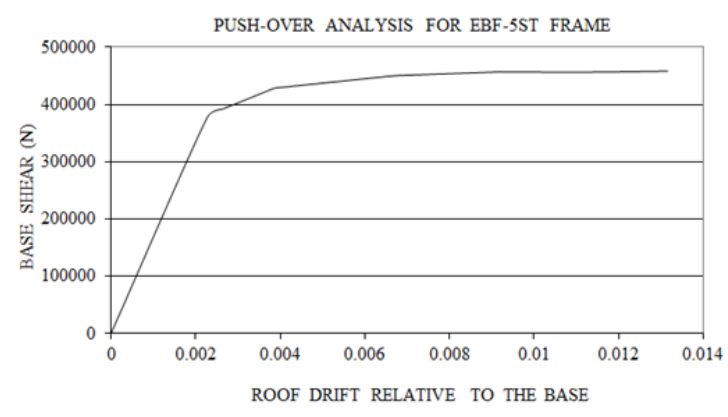

Figure 18. Push over curve for 5-story EBF 


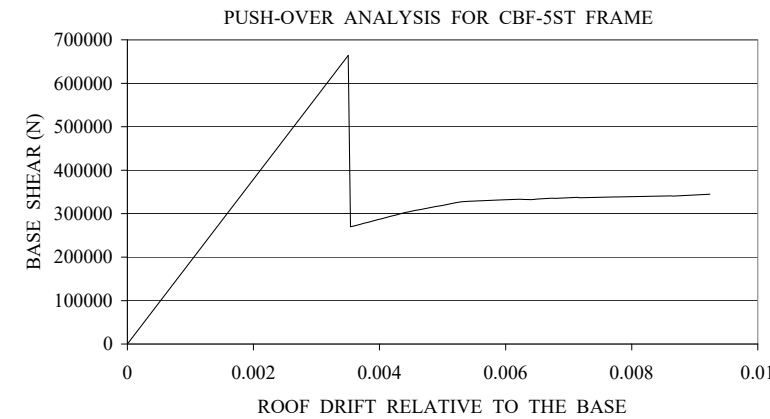

Figure 19. Push over curve for 5-story CBF

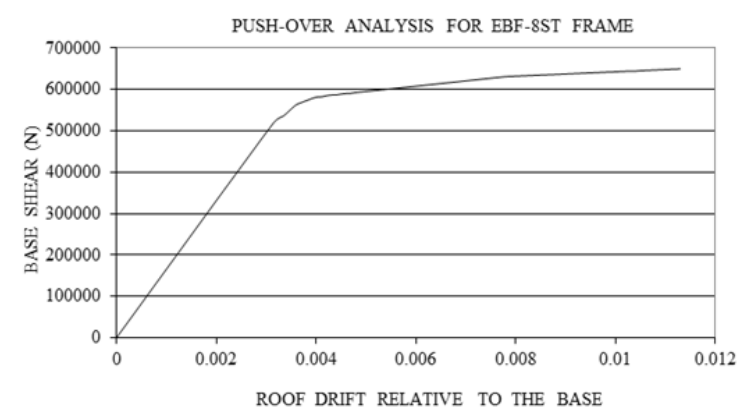

Figure 21. Push over curve for 8-story EBF

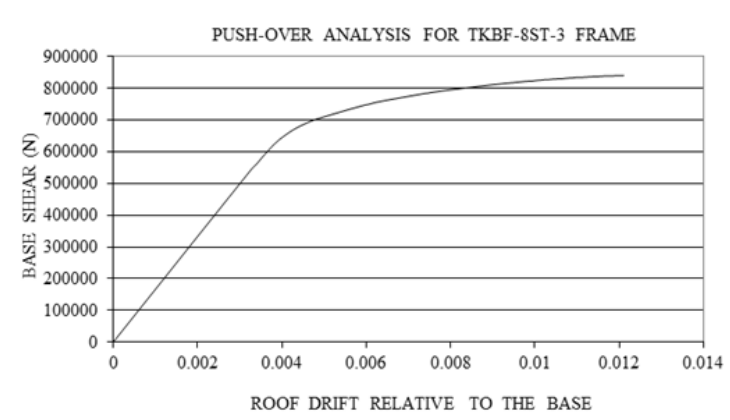

Figure 20. Push over curve for 8-story TKBF-3

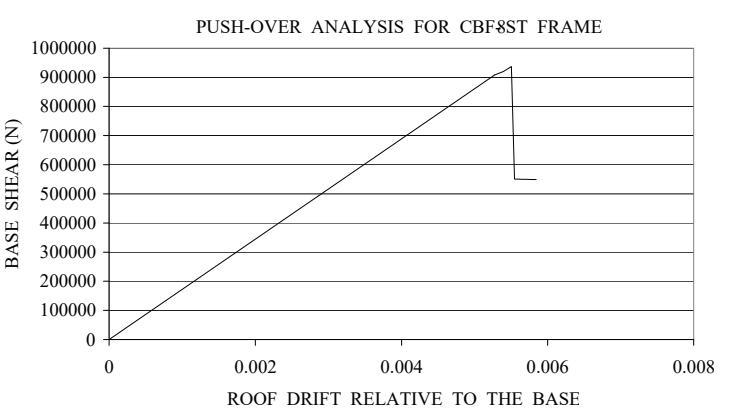

Figure 22. Push over curve for 8-story CBF

\subsection{Calculating Ductility-Related Seismic Force Reduction Factor (Ru)}

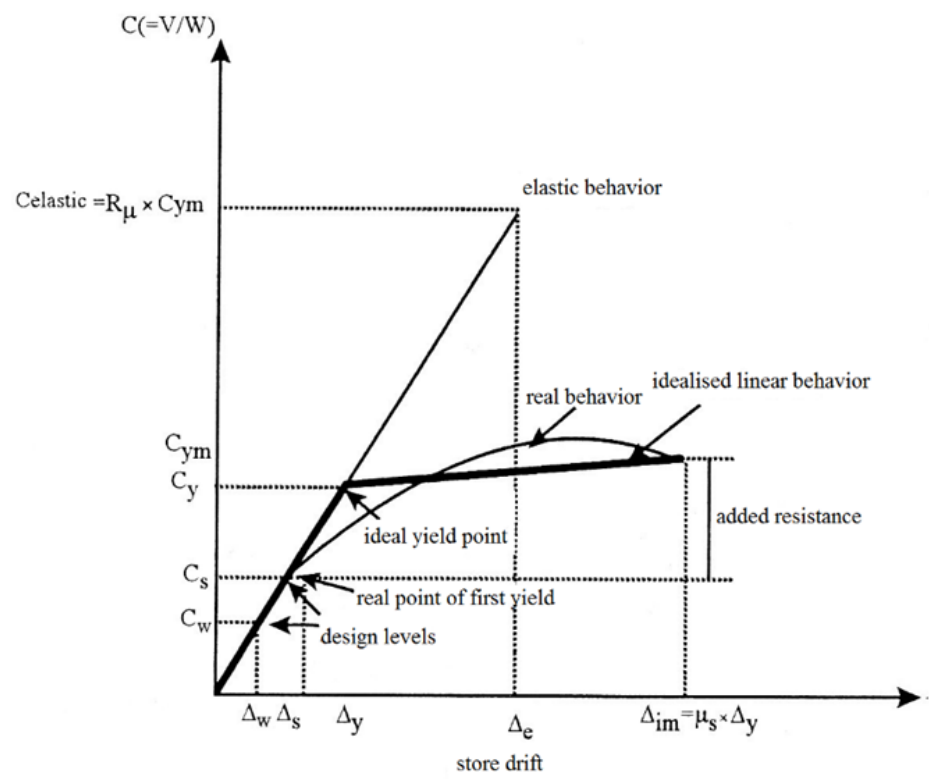

Figure 23. Parameters used to define behavior factor

According to the definition, ductility-related resistance reduction factor is defined as the ratio of elastic-required resistance to inelastic required resistance. 


$$
R_{\mu}=\frac{C_{e}}{C_{y m}}
$$

Reduction factor, $\mathrm{R} \mu$, depends on various factors including structural system, quality of connections, and number of stories. System type 1 has most influence on the above factor (Niknam, Sanaei, Hashemi, \& Baji, 2002).

Factors $\mathrm{R} \mu$ are calculated for the studied three-, five- and eight-story models using the results of Nonlinear Static Pushover (NSP) analyses and equation 2, which are shown in Tables 5 to 7. As an example, changes in R $\mu$ are shown in Fig. 24 for the studied three-story frames.

R $\mu$ FACTOR FOR 3 STORY FRAMES

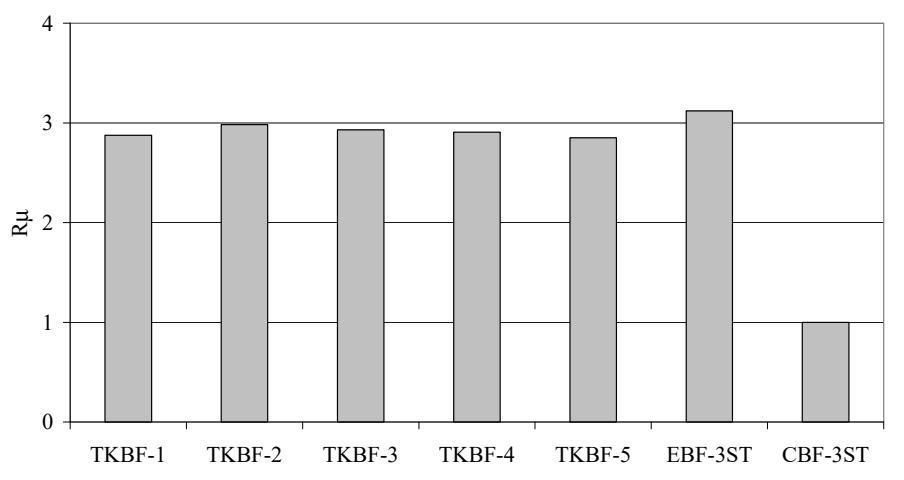

Figure 24. $\mathrm{R} \mu$ for the studied 3-story frames

\subsection{Calculating over Strength Factor (RS)}

Over strength factor is defined as the ratio of structural resistance during formation of general failure mechanism and structural resistance during formation of the first plastic joint (Eq. 3) (Chopra, 2000).

$$
R_{S}=F_{1} \cdot F_{2} \cdot F_{3} \cdot \frac{C_{y m}}{C_{s}}
$$

where,

F1 : Real yield tension to nominal yield tension ratio; value about 1.05 is recommended;

F2 : Effect of loading velocity on yield tension; value about 1.1 is recommended;

F3 : Effect of non-structures, which is considered about 1.2

This coefficient depends on factors such as redistribute ability of internal forces due to degrees of uncertainty, resistances higher than the specified levels for used materials, strain hardening, minimum procedural regulations for sizes and details of parts, and the effects of different loads and non-structural members (Niknam, Sanaei, Hashemi, \& Baji, 2002).

RS is calculated for three, five and eight-story models using Nonlinear Static Pushover (NSP) analyses and Eq. 3 (Tables 5 to 7). As an example, changes in RS are shown in Figure 25 for the studied five-story frames. 


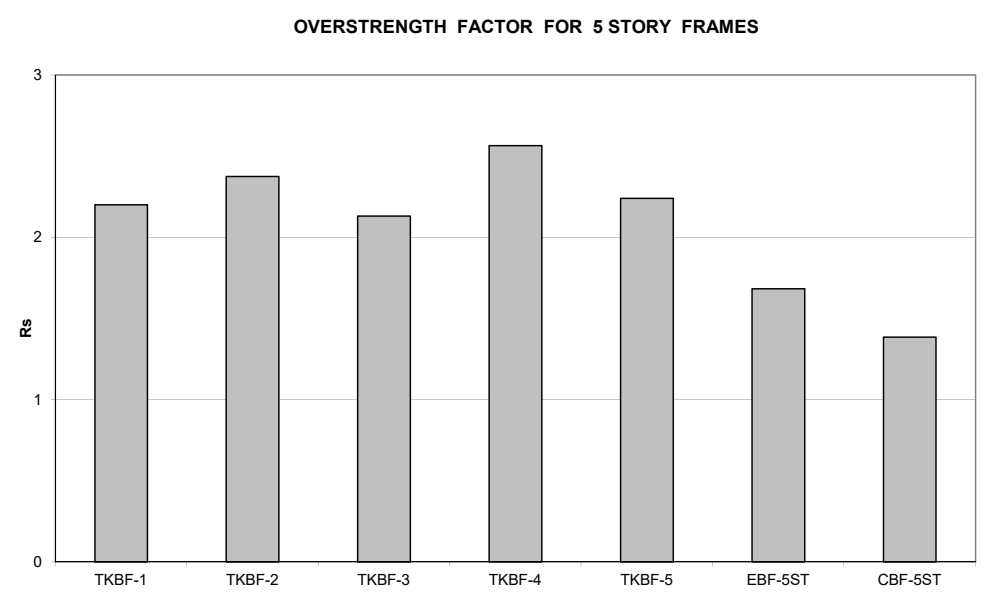

Figure 25. Over strength factor, RS, for the studied 5-story frames

\subsection{Calculating Behavior Factor (R)}

Behavior factor of the structure is defined as the ratio of structure's elastic strength (Celastic) to its design strength (Cdesign), according to Eq. 4 (Niknam, Sanaei, Hashemi, \& Baji, 2002).

$$
R=\frac{C_{\text {elastic }}}{C_{\text {design }}}
$$

Since designing is common in two levels including: (a) load factors and final strength, and (b) allowed tension; $C_{\text {design }}$ can be either CS or CW, as defined in Fig. 23. Thus, Eq. 4 can be written as: (Niknam, Sanaei, Hashemi, \& Baji, 2002)

$$
\begin{gathered}
R_{U}=\frac{C_{e}}{C_{S}}=\frac{C_{e}}{C_{y m}} \times \frac{C_{y m}}{C_{S}}=R_{\mu} \times R_{S} \\
R_{W}=\frac{C_{e}}{C_{w}}=\frac{C_{e}}{C_{y m}} \times \frac{C_{y m}}{C_{S}} \times \frac{C_{S}}{C_{w}}=R_{\mu} \times R_{S} \times Y
\end{gathered}
$$

where, RU is the behavior factor based on extreme tensions, and RW is the behavior factor based on the allowed tensions. The following equation can be considered between the two design levels: (Niknam, Sanaei, Hashemi, \& Baji, 2002)

$$
Y=\frac{R_{W}}{R_{U}}=\frac{C_{S}}{C_{W}}
$$

where, $\mathrm{Y}$ is a factor determined according to the design codes (yield tension and allowed tension). UBC 97 Code suggested its value $=1.4(\mathrm{UBC}, 1997)$.

The RU coefficients for three-, five- and eight-story models are calculated using Nonlinear Static Pushover (NSP) analyses and Eq. 5 (Tables 5 to 7). As an example, changes of RU are shown in Fig. 26 for the studied eight-story frames. The average values for RU for three-, five- and eight-story TKBFs are 7.237, 6.065 and 5.197, respectively. Disregarding to the number of stories, the average values for TKBFs are RU $=6.166$ and RW $=8.879$. Therefore, $\mathrm{RU}=6$ and $\mathrm{RW}=8.5$ can be conservatively used for TKBFs. 
REDUCTION FACTOR FOR 8 STORY FRAMES

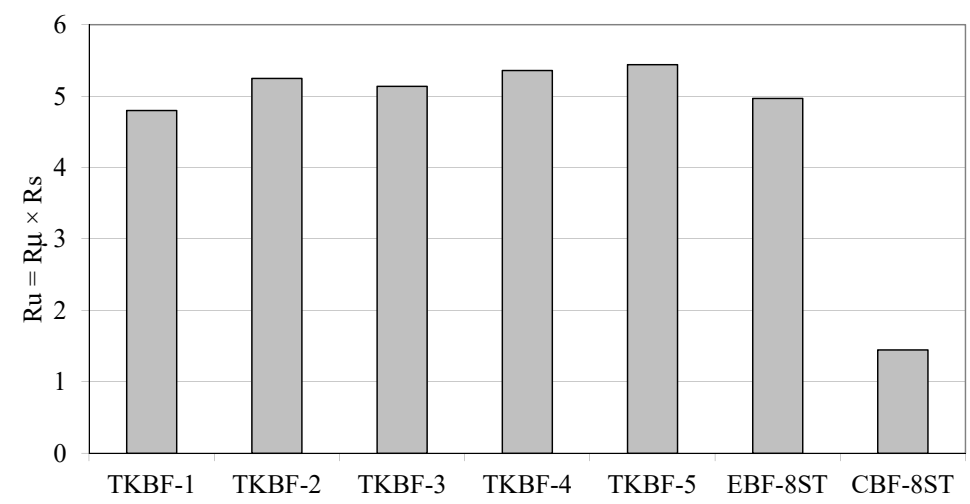

Figure 26. Behavior factor, RU, for the studied 8-story frames

Table 5. Results of nonlinear static analyses for the studied 3-story frames

\begin{tabular}{lllllll}
\hline Model & VS (N) & Vym (N) & Ve (N) & R $\mu$ & RS & RU \\
\hline TKBF-1 & 291915 & 478199 & 1375057 & 2.875 & 2.270 & 6.526 \\
TKBF-2 & 239519 & 427353 & 1275176 & 2.984 & 2.473 & 7.379 \\
TKBF-3 & 239446 & 426560 & 1250224 & 2.931 & 2.468 & 7.234 \\
TKBF-4 & 220903 & 410389 & 1193434 & 2.908 & 2.575 & 7.488 \\
TKBF-5 & 210873 & 403163 & 1149945 & 2.852 & 2.650 & 7.558 \\
EBF-3ST & 285966 & 381681 & 1191739 & 3.122 & 1.850 & 5.776 \\
CBF-3ST & 501595 & 501595 & 501595 & 1.000 & 1.386 & 1.386 \\
\hline
\end{tabular}

Table 6. Results of nonlinear static analyses for the studied 5-story frames

\begin{tabular}{lllllll}
\hline Models & VS (N) & Vym (N) & Ve (N) & R $\mu$ & RS & RU \\
\hline TKBF-1 & 384971 & 611426 & 1660309 & 2.715 & 2.201 & 5.976 \\
TKBF-2 & 344296 & 590300 & 1585298 & 2.685 & 2.376 & 6.379 \\
TKBF-3 & 383077 & 589173 & 1594246 & 2.706 & 2.132 & 5.769 \\
TKBF-4 & 313487 & 580349 & 1396427 & 2.406 & 2.565 & 6.171 \\
TKBF-5 & 333755 & 539600 & 1452268 & 2.691 & 2.241 & 6.030 \\
EBF-5ST & 377173 & 458100 & 1321215 & 2.884 & 1.683 & 4.854 \\
CBF-5ST & 663963 & 663963 & 663963 & 1.000 & 1.386 & 1.386 \\
\hline
\end{tabular}

Table 7. Results of nonlinear static analyses for the studied 8-story frames

\begin{tabular}{lllllll}
\hline Model & VS (N) & Vym $(\mathrm{N})$ & Ve $(\mathrm{N})$ & $\mathrm{R} \mu$ & $\mathrm{RS}$ & $\mathrm{RU}$ \\
\hline TKBF-1 & 605849 & 896000 & 2097430 & 2.341 & 2.050 & 4.799 \\
TKBF-2 & 549987 & 849300 & 2082665 & 2.452 & 2.140 & 5.247 \\
TKBF-3 & 543027 & 840200 & 2013078 & 2.396 & 2.144 & 5.137 \\
TKBF-4 & 513524 & 862290 & 1986315 & 2.303 & 2.327 & 5.359 \\
TKBF-5 & 487988 & 801482 & 1916808 & 2.391 & 2.276 & 5.442 \\
EBF-8ST & 519555 & 649697 & 1864030 & 2.869 & 1.732 & 4.969 \\
CBF-8ST & 908774 & 936610 & 948317 & 1.012 & 1.429 & 1.446 \\
\hline
\end{tabular}

Note. VS = Base shear of structure corresponding to first yield; Vym = Maximum base shear of nonlinear structure; $\mathrm{Ve}=$ Maximum base shear of linear structure.

\section{Conclusion}

The present study examined the lateral stiffness of multi-story TKBFs using linear static analyses. 
Ductility-related seismic force reduction factor, over strength factor, and behavior factor of traditional multi-story TKBFs were calculated by nonlinear static analyses, and were compared with the corresponding EBFs and CBFs. According to our study, the results can be summarized as follows:

The best area of $\frac{b}{B}$ and $\frac{h}{H}$ can be shown as $\left(\frac{b}{B}+\frac{h}{H}\right)<0.6,0.1<\left(\frac{b}{B}, \frac{h}{H}\right)<0.4$ for TKBFs to achieve the proper stiffness (Fig. 10).

Lateral stiffness of TKBFs increases rapidly by increment of cross-section of braces in a small range of $\frac{A}{A_{K}}\left(\frac{A}{A_{K}}<1\right)$. However, stiffness increases slowly for the larger values of $\frac{A}{A_{K}}$ and is limited to a certain extent.

Lateral stiffness of TKBFs increases rapidly by increment of moment of inertia for knee member in a small range of $\frac{I_{K}}{I_{C}}\left(\frac{I_{K}}{I_{C}}<0.07\right)$. However, stiffness increases slowly for larger values of $\frac{I_{K}}{I_{C}}$ and is limited to a certain extent.

Ductility control modes for TKBFs and EBFs are exceed the relative displacement between two stories in the code. However, ductility control modes for CBFs are brace buckling because of a ductile element (knee member and link beam) in TKBFs and EBFs that prevents buckling.

Reduction factor, $\mathrm{R} \mu$, of TKBFs is almost in the same level of EBFs and more than CBFs.

Over strength factor of TKBFs are more than EBFs and CBFs; because, uncertainty degrees are higher in TKBFs. As a result, redistribution of internal forces increases in them.

Behavior factors of TKBFs are more than those in EBFs and CBFs. According to the calculations, RW $=8.5$ can be conservatively used for ordinary flexural framing system plus knee member.

\section{Future Scope of Work}

This research is part of the $\mathrm{PhD}$ thesis of Mr. M. Anoushehei in Tarbiat Modares University.

These studies show that the seismic behavior of KBF system is better than the analogous CBF and EBF systems. Another method that has been the subject of many studies in the recent decades, is the idea of control structures. Among the various methods of control structures that have been used, passive energy dissipation systems have been widely used in recent years. Over the past two decades, use of passive energy dissipation dampers in seismic applications has been noticed. But so far, little researches have been done about use of passive energy dissipation dampers on knee bracing system. Additionally, many of the researches are theoretical, and experimental work is rare. Given that previous research shows use of passive energy dissipation dampers and use of knee bracing system, is effective in improving the seismic behavior of structures during earthquakes. Perhaps the seismic behaviors of steel structures will be perfected by both of them. This issue will be investigated in the $\mathrm{PhD}$ thesis of Mr. M. Anoushehei in Tarbiat Modares University. This research will try to study the seismic behavior of structures using a passive damper on knee braced steel frame.

Different ideas of installing a damper on knee bracing system is shown in Figure 27. The best position of the damper on knee bracing system will be determined after further investigation.

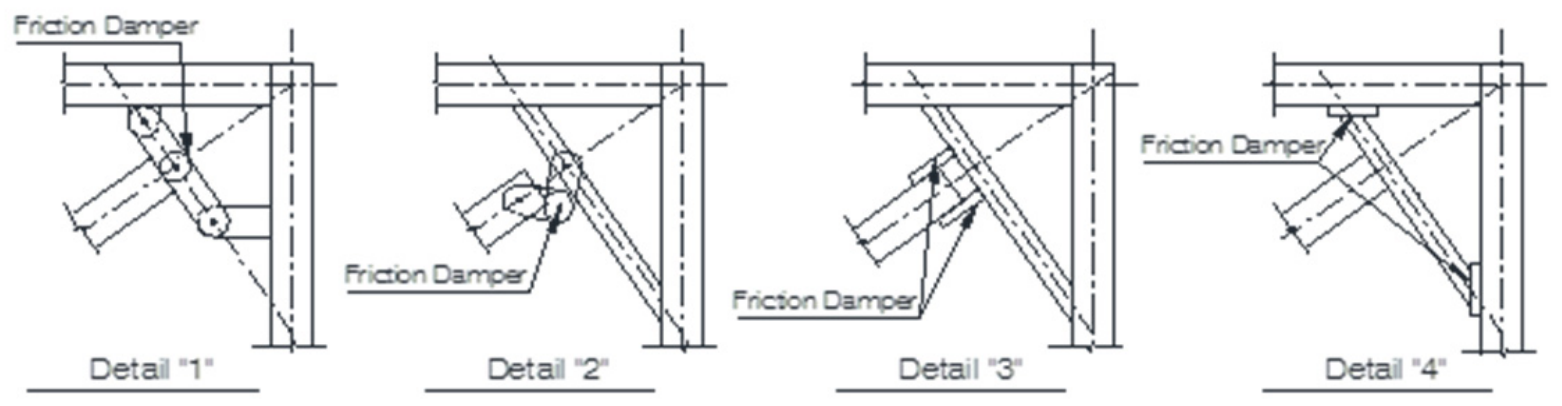

Figure 27. Different ideas of installing a damper on knee bracing system 


\section{References}

Anoushehei, M., \& Daneshjoo, F. (2005). Seismic Behavior of Multi-Story Knee-Braced Steel Frames. MS Thesis in Tarbiat Modares University, Tehran, Iran.

Balendra, T., Sam, M. T., \& Liaw, C. Y. (1990). Diagonal Brace with Ductile Knee Anchor for Aseismic Steel Frame. Earthquake Engineering and Structural Dynamics, 19, 847-858. http://dx.doi.org/10.1002/eqe.4290190606

Balendra, T., Sam, M. T., Liaw, C. Y., \& Lee, S. L. (1991). Preliminary Studies into the Behavior of Knee Braced Frames Subject to Seismic Loading. Engineering Structures, 13, 67-74. http://dx.doi.org/10.1016/0141-0296(91)90010-A

Chopra, A. (2000). Dynamics of Structures and Determination of Seismic Forces (Theory and Application) (2nd Ed.). Tehran: Elm-o-Adab Press.

Daneshjoo, F., \& Asgari, J. (2003). Nonlinear Analysis of Knee-braced Frames under Earthquake Loadings. Esteghlal, 22, 103-116.

FEMA273. (1997). NEHRP Guidelines for the Seismic Rehabilitation of Buildings, Prepared by the Applied Technology Council for the Building Seismic Safety Council. Washington, DC: Federal Emergency Management Agency.

Iranian National Building Code-Part 6 (INBC-6). (2013). Design Loads for Buildings. Ministry of Road and Urban Development, Tehran, Iran

Nateghi Elahi, F., \& Akbarzadegan, H. (1996). Seismic Behavior and Design of Eccentric Frames (1st Ed.). International Institute of Seismology and Earthquake Engineering, Tehran, Iran.

Niknam, A., Sanaei, E., Hashemi, J., \& Baji, H. (2002). Behavior and Regulation of Seismic Design for Steel Buildings (1st Ed.). Publication of Hormozgan University, Hormozgan, Iran.

Standard No. 2800. (2014). Iranian Code of Practice for Seismic Resistant Design of Buildings (4th Ed.). Building \& Housing Research Center, Tehran, Iran.

UBC. (1997). Uniform Building Code.

\section{Copyrights}

Copyright for this article is retained by the author(s), with first publication rights granted to the journal.

This is an open-access article distributed under the terms and conditions of the Creative Commons Attribution license (http://creativecommons.org/licenses/by/3.0/). 